\title{
A female case with misdiagnosis of hemophilia A who underwent total knee arthroplasty; A case report
}

\author{
Alireza Bari ${ }^{1}$ and Hassan Mansouritorghabeh ${ }^{1}$ \\ ${ }^{1}$ Affiliation not available
}

September 3, 2020

\begin{abstract}
A female with hemophilia had undergone bilateral total knee arthroplasty. She had a history of numerous hemorrhages. After further investigations, the diagnosis of von Willebrand disease type $2 \mathrm{~N}$ confirmed. The von Willebrand disease, rare bleeding disorders, and severe platelet disorders are the differential diagnoses for hemophilia A
\end{abstract}

\section{Hosted file}

A female with misdiagnosis of hemophilia A.doc available at https://authorea.com/users/ 339638/articles/478979-a-female-case-with-misdiagnosis-of-hemophilia-a-who-underwenttotal-knee-arthroplasty-a-case-report 